\title{
O SOM AO REDOR: AMBIÊNCIAS, AFETOS E TECNOLOGIAS DE ÁUDIO EM "PENNY LANE"
}

\begin{abstract}
Resumo: Este ensaio tem como objetivo compreender em que medida a dimensão material da performance vocal e das tecnologias de gravação e reprodução de áudio influi sobre o processo de construção de um tipo de experiência sensível que habitualmente denominamos como atmosfera, clima ou ambiência. Dentro dessa perspectiva, partiremos da canção "Penny Lane", dos Beatles, para pensarmos sobre as inflexões da técnica na ordem dos afetos, assim como no modo como construímos sentidos quando ouvimos uma canção e, também, na própria esfera da experiência cultural da audição.
\end{abstract}

Alex Martoni

Palavras-chave: Ambiências. Afetos. Tecnologias de áudio. Beatles. Penny Lane.

Ao refletir sobre o modo como a tecnologia digital vem embaralhando as relações entre gosto musical e experiência histórica, Simon Frith chama a atenção para o fato de que "Popular music is no longer rooted in a particular time and place but continually revived, remixed, and re-released and until it occupies a kind of virtual, history-less space" (FRITH, 2007, p. 254). Para musicólogo e cientista social inglês, os imperativos da indústria musical e suas determinações no processo de desenvolvimento das tecnologias de áudio provocam, hoje, transformações tais, na sonoridade das gravações originais das canções, que "For many of their listeners the Beatles are as much a 1990s group (when the various digitally remixed anthology albuns were released) as in a 1960s one"2 (FRITH, 2007, p. 254).

Ao indicar a presença de uma sonoridade híbrida, nas reedições dos discos dos Beatles situada, em termos estéticos e acústicos, em um entre-lugar entre os anos 60 e os 90, Frith toca em problemas agudos no que diz respeito às relações entre técnica e experiência estética no domínio da cultura musical contemporânea; problemas que envolvem tanto os influxos das determinações econômico-tecnológicas na cultura auditiva, quanto os modos pelos quais as materialidades dos meios operam no processo de construção de sentidos. Dentro dessa perspectiva, abordaremos estes problemas tendo como eixo central a seguinte questão: de que modo a construção de ambiências sonoras influi, hoje, sobre a dimensão afetiva de um ouvinte?

Tomemos, como forma de exemplificação do problema, na mesma clave de Frith, a canção "Penny Lane", dos Beatles. Por mais que ela tenha sua sonoridade alterada pelos processos de pós-produção contemporâneos, há certas qualidades acústicas e

\footnotetext{
* Doutor em Estudos de Literatura pela Universidade Federal Fluminense (UFF). Pós-Doutorando pela UFF com bolsa PNPD/Capes. E-mail: Alekzmartony@hotmail.com.

1 “A música popular já não está enraizada em um tempo e lugar específico, mas é continuamente revivida, remixada e relançada até ocupar um tipo de espaço virtual, sem história". As traduções presentes, neste artigo, foram por mim realizadas.

2 "Para muitos dos seus ouvintes, os Beatles são tanto um grupo dos anos 90 (quando vários álbuns digitalmente remixados foram lançados) quanto dos anos $60 "$ ".
} 
procedimentos estéticos que permanecem como um rastro, um componente acústicoimanente de seu registro primeiro; aspectos na ordem da performance dos músicos, do timbre dos instrumentos, dos sistemas de gravação e de pós-produção. Não é por acaso que, mesmo aos ouvidos de um neófito, é perceptível a presença de uma textura sonora e de um modo de composição que, no mínimo, soam diferentes daqueles considerados atuais. As ambiências, no âmbito musical, corresponderiam, então, a uma espécie de atmosfera, de clima, inscrito na dimensão material da obra? De que modo, reiterando nossa questão fundamental, a construção de ambiências sonoras influi, hoje, sobre a dimensão afetiva de um ouvinte? E, ainda, seria possível afirmar que essa dimensão híbrida na sonoridade de algumas canções revelam, em alguma medida, que vivemos um presente invadido pelas reverberações das ambiências do passado?

Nossa exposição se dará em três etapas. Começaremos introduzindo a noção do que exatamente circunscrevemos com a palavra ambiência com o objetivo de pensá-la como categoria que nos permitiria operar, metodologicamente, sobre os diversos aspectos que compõem a dimensão material de uma canção. Em seguida, vamos nos dedicar, mais efetivamente, à análise daquilo que estamos chamando de "fenômenos materiais" responsáveis pela construção das ambiências de "Penny Lane": a voz em performance, os sistemas de gravação (em especial, o wall of sound) e de pós-produção, articulados com os de audição (particularmente, o $h i-f i$ ). Ao final, retomaremos o problema apresentado por Frith, tentando indicar, agora de forma mais precisa, as implicações dessa natureza híbrida das canções remasterizadas na esfera da relação entre técnica e experiência estética no mundo contemporâneo.

\section{AMBIÊNCIAS SONORAS}

Comecemos com a seguinte hipótese: se eu não compreendo a língua inglesa, não consigo, evidentemente, colocar em movimento o circuito significante-significado ativado pela letra de "Penny Lane". Para mim, esta canção poderia ser sobre uma paixão atual, o processo de envelhecimento ou a própria arte de compor canções. Tampouco as questões relativas à estrutura musical me são conhecidas; eu não sei o que é um compasso de 4/4 e não consigo reconhecer o encadeamento de notas; aliás, não tenho a competência de saber nem mesmo quais são os instrumentos que são tocados na canção. Em suma, ainda que ignore os códigos das linguagens verbal e musical, consigo sentir uma certa qualidade intensiva no modo como é cantada, uma suavidade na maneira como é tocada, uma sensação de preenchimento dos espaços quando chega o refrão. Neste caso, "Penny Lane", para mim, não se realiza a partir de um processo de atribuição de significados a significantes, mas como um fluxo de estímulos sensoriais, de "blocos de sensações" - para pensarmos com Deleuze (1992) -, cuja ressonância em nosso corpo produz forças de encontro que mobilizam nosso sistema sensório-motor e, concomitantemente, a experiência subjetiva do sujeito. Seria possível denominar este sistema de forças que nos envolve e atua sobre os nossos sistemas físico e psíquico como ambiência?

$\mathrm{Na}$ medida em que estamos lidando com o universo tecnológico da produção musical, falar em ambiência pode soar como uma afirmação tautológica, tendo em vista 
que parte do trabalho de produção, neste domínio, é, efetivamente, um processo de preparação de um ambiente para a captação de determinados fenômenos acústicos, tal como a descrição que George Martin faz sobre o término das gravações do álbum Sergeant Pepper's Lonely Hearts Club Band (1967), dos Beatles, nos permite observar:

\begin{abstract}
When the last note from the end section had finished, the engineer Geoff Emerick pushed up the faders in order to pick up every lingering sound until, after forty-one seconds, all you could hear was the air conditioning ${ }^{3}$. (BADMAN, 2000, p. 266).
\end{abstract}

Como se vê, o trabalho desenvolvido nos estúdios de gravação de áudio é, fundamentalmente, uma atividade voltada à construção de formas variadas de percepções sonoras. Assim como George Martin, na última sessão do disco Sergeant Pepper's Lonely Hearts Club Band, deixou que os microfones captassem a reverberação final dos instrumentos até que só se ouvisse o som do ar condicionado, faz parte do repertório técnico dos produtores musicais manipular concretamente o espaço da gravação com, por exemplo, o uso de colchões em torno dos microfones para abafar um som e torná-lo, desse modo, mais "quente"; ou inserir recursos oferecidos pelos aparatos técnicos, como eco, delay e reverb ${ }^{4}$ em uma voz, tornando-a mais "etérea". O resultado desse processo de manipulação do espaço com o objetivo de se construir certas qualidades auditivas é chamado, justamente, na linguagem técnica, de ambiência.

Contudo, para além do seu uso corrente no âmbito da produção musical, a própria história semântica do vocábulo parece também acolher essa noção de um contato substancial do sujeito com a dimensão material que o envolve. De acordo com Leo Spitzer (SPITZER, 1968), a palavra ambiência, deriva de um processo de latinização da palavra grega $\pi \varepsilon \rho t \varepsilon ́ \chi 0 v^{5}$, ocorrido durante o renascimento italiano, período em que os termos latinos ambire e ambiens locum foram concebidos como forma de tradução deste vocábulo grego, originalmente entendido como aquilo que "surrounds, encompasses"6 (SPITZER, 1968, p. 180). Mas Spitzer também localiza, neste vocábulo grego, uma relação de parentesco semântico com a palavra alemã Stimmung, lexicologicamente constituída no século XVIII; relação que nos estimula a refletir, em caráter especulativo, se seria possível pensar o que estamos chamando de ambiência na mesma clave semântica do referido vocábulo alemão. No âmbito literário, essa foi, justamente, a proposta apresentada pelo teórico da literatura e da cultura Hans Ulrich Gumbrecht.

\footnotetext{
3 "Quando a última nota da sessão final terminou, o engenheiro Geoff Emerick arrastou os potenciômetros para cima no intuito de capturar todos os sons restantes, até que, após quarenta e um segundos, tudo o que se podia ouvir era somente o ar condicionado".

${ }^{4}$ O delay é um meio técnico de manipulação do som em que altera a velocidade de emissão de uma frequência, sempre retardando-a; já o reverb consiste em um efeito através do qual um som persiste depois de sua emissão ter sido encerrada. Ambos os efeitos podem ser ouvidos no tratamento das vozes e dos instrumentos nas canções do disco Sergeant Pepper's Lonely Hearts Club Band (1967), dos Beatles.

$5 \mathrm{Na}$ transliteração para o alfabeto romano, Periekhon. Etimologicamente, a palavra é formada pela justaposição de $\pi \varepsilon \rho l$ (peri) significa "em torno", "ao redor" com $\varepsilon$ ¿ov (ekhon), cujo sentido é "agarrar" - normalmente associado a aer, "ar". Seu significado, portanto, seria algo próximo a "o que está ao redor", "o ar ao redor", "aquilo que me envolve".

6 "circunda, rodeia".
} 
Recentemente, no livro Atmosfera, ambiência, Stimmung (2014), Gumbrecht propôs o desenvolvimento de um modo de leitura voltado àquilo que ele entende como "um potencial oculto da literatura" (GUMBRECHT, 2014, p.14); isto é, uma capacidade que a palavra, na sua própria materialidade, teria de despertar certas modulações afetivas no leitor. Nesse sentido, conclui Gumbrecht, "'Ler com a atenção voltada ao Stimmung' sempre significa prestar atenção à dimensão textual das formas que nos envolvem, que envolvem nossos corpos, enquanto realidade física" (2014, p. 14). Ainda que possa, metaforicamente, ser aproximada dos vocábulos atmosfera, clima e ambiência, a palavra alemã Stimmung - é importante salientar - possui uma singularidade semântica, tendo em vista que, ainda segundo Spitzer, "para um alemão, Stimmung está fundida com a paisagem, a qual, por sua vez, está animada pelo sentimento do homem: é uma unidade indissolúvel em que homem e natureza estão integrados" (2008, p. 15). Ora, se partirmos da ideia de que o fenômeno da audição envolve a emissão de ondas acústicas, através de dispositivos técnicos, que ricocheteiam por um espaço tecnicamente construído, entrando em contato substancial com os nossos corpos, nos parece, então, legítimo aproximar, no âmbito da música, a noção de ambiência à de Stimmung. Parece ser, justamente, aí, numa zona de encontro entre a ressonância da dimensão material do som, o modo como nossos corpos o apreendem e os processos psíquicos daí deflagrados que buscamos, na insuficiência das palavras, apreender, ainda que de forma cediça e fugaz, a experiência da imersão em uma ambiência acústica.

Ao analisar as impressões provocadas pelo som orquestral que irrompe no meio da canção "A day in the life", dos Beatles, por exemplo, o jornalista André Singer afirma que essa massa sonora simula "a vertigem de quem cai, ou afunda, no sono" (SINGER, 2007, p. 61); já Daniel Levitin, ao ouvir a canção "Green River", do grupo Creedence Clearwater Revival, afirma encontrar em sua sonoridade "O clima turvo típico do Sul Profundo" (LEVITIN, 2010, p. 8) dos EUA; Celso Favaretto, por sua vez, aponta que o trecho inicial de "Tropicália", de Caetano Veloso, apresenta um "clima "tropical"" (FAVARETTO, 2000, p. 65). Depoimentos como estes trazem a instigante questão de como é que atribuímos sentidos aos sons; isto é, por que é que associamos os sons instáveis dos violinos de "A day in the life" com a "vertigem"? O que é que há na relação baixo/guitarra/bateria/voz da canção do Creedence que nos remete a um suposto "clima turvo" de uma região dos EUA? De que modo os timbres e ritmos das percussões de "Tropicália" contribuem na construção dessa impressão de um "clima tropical"? É inequívoco que o estabelecimento de relações estáveis entre "significantes sonoros" e "significados psíquicos" consistiria em um modo reducionista de pensar toda a complexidade e singularidade da relação entre percepção e experiência.

Não obstante os obstáculos que este problema impõe ao processo analítico, parece-nos, ainda assim, produtivo refletir sobre esta espécie lógica da sensação - aqui, uma vez mais em diálogo com Deleuze - que influi no processo como atribuímos sentidos aos sons. A música, como afirma o filósofo francês, "atravessa profundamente nossos corpos e nos põe uma orelha no ventre, nos pulmões etc. Ela é mestra em onda e nervosidade" (DELEUZE, 2007, p. 60). É essa força que ela provoca sobre os nossos corpos que, não obstante se esquivar de enquadramentos universalistas, parece admitir o 
compartilhamento de descrições e associações metafóricas ou sinestésicas. Quando José Miguel Wisnik expõe, por exemplo, que tendemos relacionar as vibrações mais lentas do som grave com o "peso da matéria, com os objetos mais presos à terra pela lei da gravidade" (WISNIK, 1989, p. 21) e as vibrações mais rápidas do som agudo à "ligeireza leve e lépida" (1989, p. 21), parecem-nos modos bastante razoáveis de figuração da forma como percebemos esses fenômenos acústicos. Dentro dessa perspectiva, a equalização dos níveis de grave, médio e agudo, a distribuição dos instrumentos e das vozes por dois canais de emissão, e o volume individual dos mesmos na mixagem envolvem escolhas técnicas que, tais como o matiz de vermelho em um quadro, as objetivas empregadas em um filme e a fonte de um texto, podem não ser determinantes, mas, em alguma medida, influem sobre nossa percepção e no modo como construímos sentidos acerca das obras de arte. Portanto, chamaremos de ambiências esse continuum entre um espaço-tempo tecnicamente construído à percepção e os atos de engajamento afetivo que nele se desenvolvem.

A relevância de adotar as ambiências como fenômeno ao qual devemos voltar nossa atenção se dá no fato de que pensar sobre as mesmas nos permite refletir, de forma mais direcionada, sobre o tipo de experiência que a técnica nos dá. Walter Benjamin, ainda nos anos 30, chamava a atenção sobre como, "No decorrer de longos períodos históricos, modifica-se não só o modo de existência das coletividades humanas, mas também a sua forma de percepção" (BENJAMIN, p. 13). No âmbito da música, há muitos testemunhos que ilustram a tese de Benjamin: o especialista em psicologia da comunicação eletrônica, Daniel Levitin, por exemplo, ao descrever suas primeiras experiências auditivas com fones de ouvido, no final da década de 60 , relata que, para ele, a partir daquele momento, "ouvir discos já não era uma questão de estar ligado apenas nas canções, mas também no som" (LEVITIN, 2010, p. 8); opinião que, ainda segundo Levitin, era compartilhada com o músico Paul Simon, que lhe confidenciara, certa vez, o seguinte fato: "Quando ouço meus discos, minha atenção se volta para o som, não para os acordes ou as letras - minha primeira impressão é a do som global da gravação" (LEVITIN, 2010, p. 8); isto é, aquilo que estamos chamando de ambiência.

O desenvolvimento das tecnologias de registro e difusão musical, oriundos da expansão da indústria fonográfica, possibilitou a construção de ambiências muito peculiares em "Penny Lane". Neste sentido, propomo-nos a pensar sobre essa questão em três dimensões: a da performance, através da qual o músico transmite uma vibração nervosa no modo de manipulação da voz e dos instrumentos; a dos sistemas de gravação e pós-produção, responsáveis por criar uma determinada atmosfera acústica predominante na canção; e, por fim, as condições técnicas e espaciais de audição, que, de alguma forma, influem sobre os procedimentos técnicos e estéticos empregados na pós-produção.

LETRA, VOZ E PERFORMANCE

\author{
Penny Lane
}


(John Lennon e Paul McCartney)

Penny Lane there is a barber showing photographs

Of every head he's had the pleasure to have known

And all the people that come and go

Stop and say hello

On the corner is a banker with a motor car

The little children laugh at him behind his back

And the banker never wears a mac

In the pouring rain

Very strange

Penny lane is in my ears and in my eyes

There beneath the blue suburban skies

I sit and meanwhile back

In Penny Lane there is a fireman with an hourglass

And in his pocket is a portrait of the queen

He likes to keep his fire engine clean

It's a clean machine

Penny Lane is in my ears and in my eyes

A four of fish and finger pies

In summer, meanwhile back

Behind the shelter in the middle of the roundabout

The pretty nurse is selling poppies from a tray

And though she feels as if she's in a play

She is anyway

Penny Lane the barber shaves another customer

We see the banker sitting waiting for a trim

And then the fireman rushes in

From the pouring rain

Very strange

Penny Lane is in my ears and in my eyes (2x)

There beneath the blue suburban skies $(2 \mathrm{x})$

Penny Lane ${ }^{7}$.

Lançada, originalmente, como lado B do single "Strawberry fields forever", em fevereiro de 1967, "Penny Lane" é, fundamentalmente, uma marchinha pop construída

\footnotetext{
${ }^{7}$ Transcrição feita a partir da versão cifrada - que se encontra nas duas páginas seguintes. Beatles complete chord songbook. Milwaukee: Wise Publications, 1999. pp.262-263.
} 
no compasso de 4/4 e que apresenta uma alternância regular entre as estrofes e os refrãos, com a irrupção, no meio da canção, de um solo de trompete piccolo. Em sua última parte, ocorre a repetição do refrão já marcada por um crescendo final, concebido como uma parede sonora de vozes e instrumentos orquestrais. Desse modo, a canção tensiona os limites do que, até então, era convencionalmente entendido como pop, revelando-se como uma obra de grande refinamento musical, devido à presença de instrumentos orquestrais e das técnicas de gravação e pós-produção extremamente modernas. Esse nível de sofisticação na produção de canções como "Penny Lane" e "Strawberry fields forever", dentre várias outras gravadas nas mesmas sessões do revolucionário álbum Sergeant Pepper's Lonely Hearts Club Band - suscitaram uma indagação do musicólogo inglês Alan Moore, que se perguntou se um "futuro dicionário de música teria uma entrada para 'Sergeant Pepper' em algum lugar entre 'Schoenberg' e 'Sprechstimme'?” (MOORE, 1997).

Sob o ponto de vista da relação entre letra e voz, a estrutura da canção alterna, basicamente, duas modulações rítmicas: a das estrofes, em que o andamento de marcha acompanha o processo descritivo do dia a dia da classe trabalhadora de uma cidade de porte médio do norte da Inglaterra e a dos refrãos, em que somos apresentados às reflexões de um observador sobre o modo como estas cenas se encontram impregnadas em seus sentidos - parte que é acompanhada por uma polifonia vocal e pelo floreio de instrumentos orquestrais.

Nas estrofes, o sujeito poético observa e descreve, de forma atenta e fragmentada, o vai-e-vem das pessoas por Penny Lane e, desse modo, produz, como em uma fotografia, flagrantes que conferem imortalidade ao efêmero, relevância aos aspectos mais prosaicos do dia a dia, como a troca de cumprimentos entre um barbeiro e os transeuntes, os risos das crianças pelo fato de o banqueiro nunca usar capa quando chove forte, as manias de um bombeiro que carrega a foto da rainha no bolso e que gosta de manter o seu caminhão sempre limpo e os gestos performáticos de uma enfermeira que vende papoulas em uma bandeja. O elemento que dá relevância e singularidade a estes short cuts da vida cotidiana de Penny Lane é o fato de que eles compõem as memórias afetivas do observador - conforme o refrão virá a revelar. Nas estrofes, o emprego dos dêiticos "There", "On the corner" e "Behind" acusam a presença deste observador que se coloca na própria cena, que situa os fatos descritos tendo como referência a sua própria localização espacial. Desse modo, o locutor apresenta uma capacidade de se propor como sujeito $^{8}$; isto é, de configurar, através da linguagem, um olhar que é conduzido por um desejo, que busca, como um voyer, uma condição privilegiada para flagrar essas pequenas vicissitudes dos personagens que transitam por Penny Lane.

Sob o ponto de vista da voz, há diferenças entoacionais que dialogam diretamente com as duas modulações afetivas predominantes na canção. É importante ratificar que,

\footnotetext{
${ }^{8}$ A noção de sujeito que trabalhamos aqui está fundada nos apontamentos de Émile Benveniste, para o qual "É na linguagem e pela linguagem que o homem se constitui como sujeito; porque só a linguagem fundamenta na realidade, na sua realidade que é a do ser, o conceito de "ego". [...] A "subjetividade" de que tratamos aqui é a capacidade de se propor como "sujeito". BENVENISTE, Émile. Problemas de linguística geral I. Campinas, SP: Pontes Editores, 2005. p.286.
} 
quando falamos, aqui, em voz, não nos referimos exatamente a uma categoria semiológica, mas tomamos a palavra em seu sentido mais literal: como presença física concretamente perceptível à audição. E, neste sentido, cabe uma pequena nota sobre as implicações dos modos de interação entre fonação e sistema psíquico.

Para produzir a voz, é fundamental lembrar, uma pessoa coloca em ação mais da metade do corpo: do abdômen à cabeça. Essa atividade neuromuscular envolve tanto mudanças no processo respiratório, particularmente nos pulsos torácicos, como nos modos de articular a glote e as cavidades supraglotais (faringal, nasofaringal, nasal, oral e labial). Uma vez que a voz é produzida a partir de uma atividade neuromuscular, ela está sujeita a ação de fenômenos físico-psíquicos que afetam o corpo daquele que a produz. É justamente por essa capacidade de sugerir estados psíquicos a partir da conformação da matéria sonora que a performance vocal de Paul McCartney se inscreve como um elemento fundamental na construção das ambiências da canção. Vejamos, de forma mais detida, como essa voz se comporta em "Penny Lane".

Ao esquadrinhar as idiossincrasias dos frequentadores de Penny Lane, o sujeito poético, de um modo bem similar à poesia moderna, extrai lirismo dos fatos mais banais que compreendem a vida cotidiana e, dessa forma, sua voz apresenta o seguinte contorno melódico:

$1^{\mathrm{a}}$ sequência $^{9}$ (estrofes)

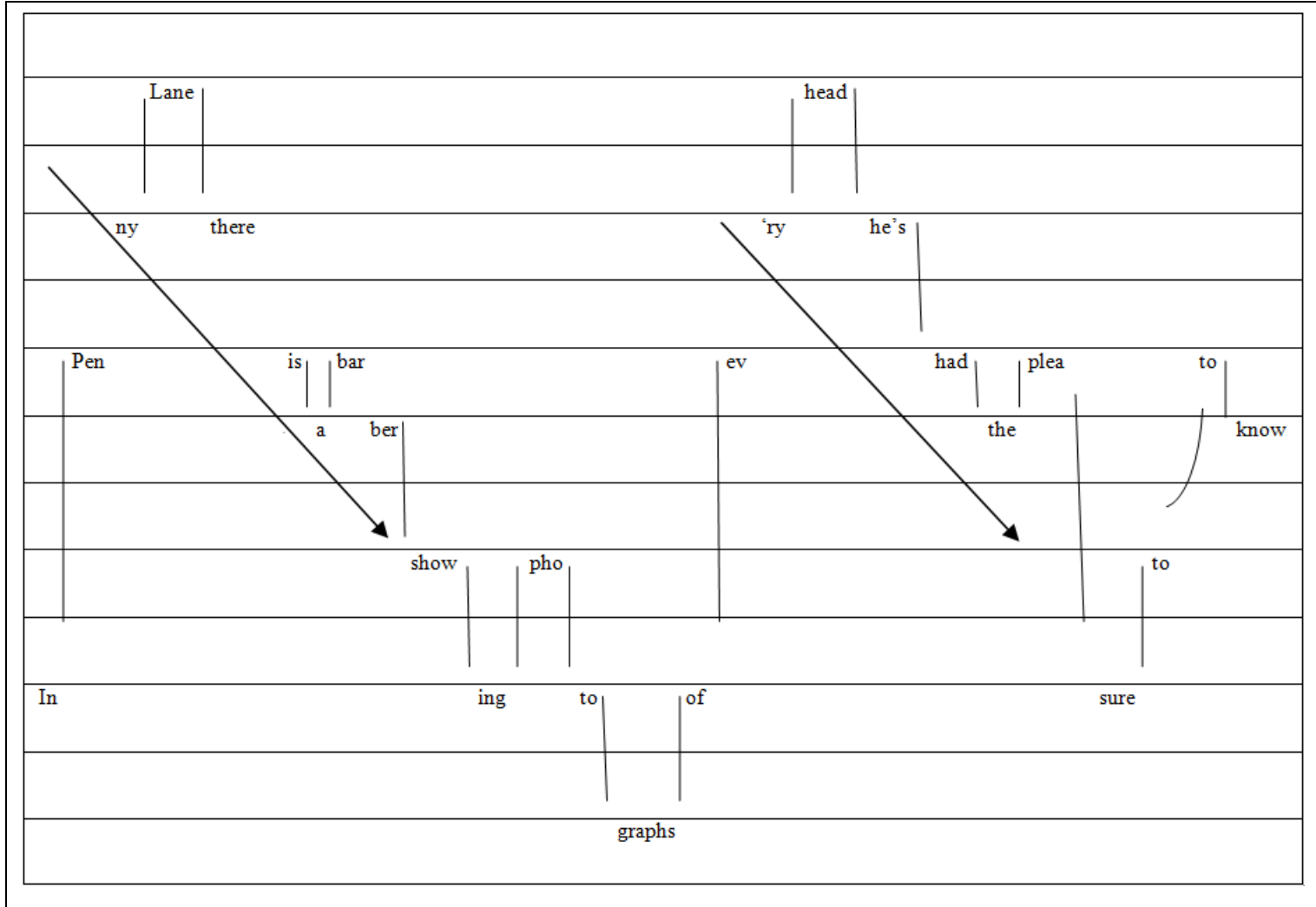

\footnotetext{
${ }^{9}$ Seguimos, aqui, o modelo de diagramas proposto por Luiz Tatit (TATIT, Luiz. Elos de melodia e letra. Cotia, SP: Ateliê Editorial, 2008), através do qual é possível transcrever simultaneamente melodia e letra. Cada linha do diagrama equivale a um semitom.
} 
O diagrama acima nos permite visualizar como a performance vocal busca, através da reiteração de um ciclo melódico, apresentar os diversos aspectos que compõem o objeto da observação do sujeito: Penny Lane. É nesse sentido que há uma reiteração do tema - "tematização melódica", na terminologia de Luiz Tatit (TATIT, 2008 , p. 22) -, que se dá não só na enumeração das cenas que se entrecortam no dia a dia da rua, mas também na enfatização da melodia vocal. O desenho melódico da voz, em gradação descendente (como as setas do diagrama mostram), segue a própria estrutura musical, em que as estrofes são organizadas em andamento de marcha ${ }^{10}$, como se buscassem, através do piano em staccato e da cadência fortemente marcada, no baixo e na bateria, simular o ritmo da vida cotidiana, dos passos que marcam o entra e sai de pessoas por Penny Lane. Desse modo, há uma espécie de relação de pertinência entre a dimensão semântica da letra e a materialidade do desenho acústico dada pelas inflexões vocálicas.

Nos refrãos, o sujeito poético afasta-se do plano da observação para o da autoconsciência de que tudo aquilo que é dito permanece vivo na memória; está impregnado em seus sentidos - "Penny Lane is in my ears and in my eyes" - e é modulado pelas condições climáticas que pairam sobre a rua: "There beneath the blue suburban skies". O diagrama abaixo nos permite visualizar como a mudança da estrofe para o refrão implica, também, uma transformação no desenho melódico da voz:

$2^{\mathrm{a}}$ sequência (refrãos)

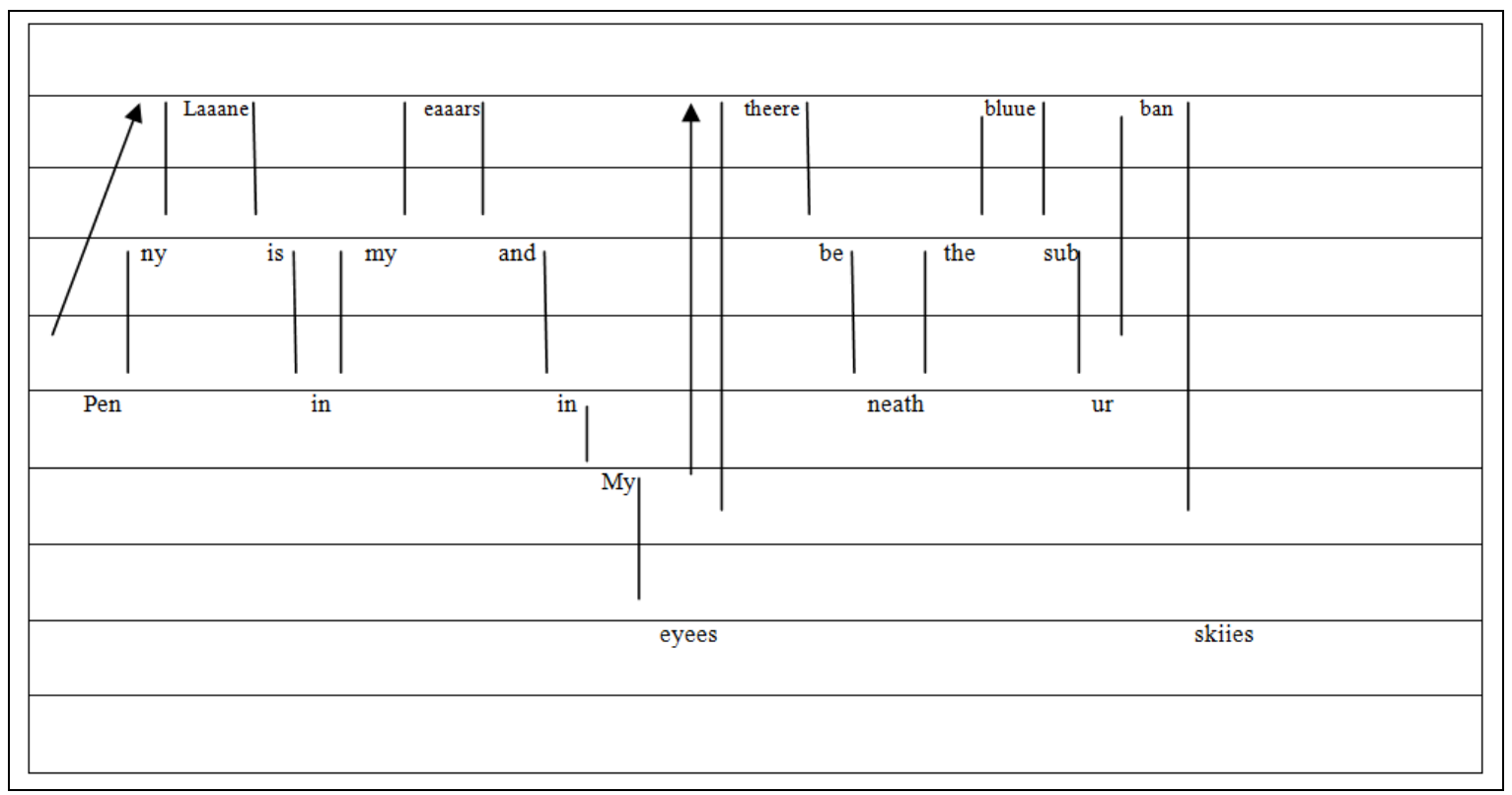

10 Segundo o Dicionário Sesc de Cultura, "Forma ou composição destinada a um acompanhamento processional, cadenciado de pessoas dispostas em séquitos, cortejos ou desfiles. Pode ter um tratamento erudito ou popular, assim como possuir um andamento lento ou solene (compasso 4/4) ou mais acelerado (2/4). As mais comuns são as nupciais, as militares, as fúnebres, as de fanfarras e, no Brasil, as carnavalescas (também chamadas marchinhas e a marcha-rancho)". CUNHA, Newton. Dicionário Sesc: a linguagem da cultura. São Paulo: Perspectiva: Sesc São Paulo, 2003, p. 404. 
Nos refrãos de "Penny Lane", há a entrada de camadas de vozes e instrumentos orquestrais que conferem densidade e complexidade harmônica à canção no exato momento em que o processo de impostação da voz parece sugerir um aumento do quantum afetivo do enunciador. Essa mudança do processo de tematização para o de passionalização $^{11}$ provoca, pelo menos, três mudanças perceptíveis no desenho melódico da voz: em primeiro lugar, se compararmos o diagrama da primeira sequência com o da segunda, fica evidente que a voz trabalha em uma região mais alta da escala, saindo do mais grave para o mais agudo; em segundo, é possível perceber uma tendência "verticalizante" do contorno melódico, com saltos intervalares mais abruptos, e não em escala, como nas estrofes. Luiz Tatit destaca que "os intervalos distantes entre as notas exigem um esforço de emissão que realça o estado emotivo do cantor" (TATIT, 2008, p. 12). Nesse sentido, a força expressiva já está inscrita na própria materialidade do corpo; é o corpo que vibra com pujança entre notas mais baixas e mais altas; ou que provoca uma valorização das durações vocálicas, provocando o prolongamento das vogais das palavras que se encontram no topo do movimento ascendente da voz. Desse modo, o sujeito poético passa de uma descrição do lugar para uma autorevelação afetiva da própria experiência do lugar. Em alguma medida, o fenômeno da voz pode ser pensado na mesma perspectiva em que Hans Ulrich Gumbrecht situou a voz de Janis Joplin na canção "Me and Bobby McGee”. Nela, segundo o teórico,

As emoções, atmosferas e estados de espírito que uma voz tão poderosa convoca estão assegurados; qualquer um que tenha ouvido a música os identifica, mesmo na falta de conceitos que possam permitir entendê-los e dividi-los com outros de maneira descritiva (GUMBRECHT, 2014, p. 126).

A performance vocal de Paul McCartney, com suas modulações entoativas, variações de volume e floreios melódicos nos convoca, também, para uma experiência atmosférica. É no ato de produção dessa voz que os estados psíquicos ganham forma e reverberam sobre os nossos corpos. E é na afinação entre o corpo que fala e o que ouve que irrompe a ambiência.

\section{WALL OF SOUND}

Voltemos ao refrão de "Penny Lane". Como vimos, no plano semântico, ele marca uma ruptura com o processo descritivo correspondente às cenas do cotidiano da referida rua para introduzir, tanto na ordem semântica, quanto na da performance vocal, a dimensão afetiva do enunciador que a contempla: "Penny Lane is in my ears and my eyes". Esse processo de aumento quantitativo nos modos de expressão dos afetos, de certa forma, próximos à noção de passionalização, em Tatit, é acompanhando, no plano musical, por um crescendo formado pela adição de diversos instrumentos tocando em uníssono. Enquanto a textura musical das estrofes é constituída por harmonias

\footnotetext{
${ }^{11}$ Para Luiz Tatit, "Na letra, temos em geral a descrição dos estados passionais que acusam a ausência do outro, o sentimento (presente, passado ou futuro) de distância, de perda, e a necessidade de reconquista". TATIT, Luiz. Elos de melodia e letra. Cotia, SP: Ateliê Editorial, 2008, p. 21.
} 
produzidas pelo encontro de instrumentos usualmente empregados no gênero rock, como baixo, guitarra, bateria e piano; nos refrãos, emergem, subitamente, sonoridades que não necessariamente frequentavam, até então, essa seara, como flautas, trompetes, piccolos $^{12}$ e oboés. Todos, juntos, formam uma complexidade harmônica, dão densidade ao modo como a percebemos auditivamente, ao preencherem diferentes regiões do espectro sonoro em termos de frequências, alturas e timbres. Ao comentar como essa parte foi gravada, George Martin revela alguns detalhes a respeito de como esses instrumentos foram sendo incorporados à canção:

\begin{abstract}
They were always asking me about instruments of the orquestra. I introduced them to a bassoon, bass clarinet, or whatever, but I had never introduced them to a Bach trumpet. But Paul, one evening, watched on television, a Bach Brandenburg Concerto and he came to me the following day, and said, 'Great sound I heard last night, a tremendously high trumpet'. 'Yes,' I said, 'it's a Bach trumpet.' 'Can we use it,' he asked. 'Yes, of course we can,' I replied. It never ocurred to me, but it ocurred to him. So, we got the guy from the LSO (London Symphony Orquestra - David Mason) to play piccolo trumpet and that was that."

13 (BADMAN, 2000, p. 281).
\end{abstract}

Essa técnica empregada por Martin, a partir da qual os instrumentos orquestrais que apareciam eram incorporados ao refrão, ocupando as várias regiões do espectro acústico e sugerindo, ao ouvinte, uma sensação de preenchimento de todos os espaços sonoros tinha sido desenvolvida poucos anos antes da gravação de "Penny Lane" e recebera o sugestivo nome de wall of sound. O produtor musical que a desenvolvera, Phil Spector, não escondia sua ambição, ao revelar aos músicos e técnicos com os quais trabalhava que "Listening to a symphony orquestra play 'The ride of the Valkyries' or the ' 1812 Overture' it was as if you could hear great armies on the march. Why couldn't a rock and roll record sound as big, as powerful, as thrilling as that?"14 (BROWN, 2008, p. 111). Esse desejo de Phil Spector de dar ao rock a mesma pujança sonora de uma orquestra levou o baterista Hal Blaine a definir essa experiência através de um inspirado trocadilho: "I used to call it the Phil-harmonic". (BROWN, 2008, p. 113).

Desde o fim de 1962, o produtor começou a reunir, em torno de si, uma equipe de cerca de 25 músicos: três guitarristas, três baixistas, dois saxofonistas, um baterista, um percursionista, além de pianistas e músicos de orquestra. Deles eram exigidas longas

\footnotetext{
12 Usamos, aqui, o termo original, do italiano, por ser mais conhecido. Há, contudo, uma tradução possível para o português, flautim, que, de acordo com o Dicionário Houaiss, é um "instrumento sopranino da família das flautas transversas". HOUAISS, Antônio; VILLAR, Mauro de Salles. Dicionário Houaiss da Língua Portuguesa. Rio de Janeiro: Objetiva, 2001. p. 1355.

13 "Eles estavam sempre me perguntando sobre instrumentos de orquestra. Eu lhes apresentei um baixo, uma clarineta e tudo mais, mas eu nunca lhes tinha apresentado um trompete piccolo. Mas Paul, uma noite, assistiu na televisão a um concerto da Bach Brandenberg e chegou para mim no dia seguinte e disse, 'Eu ouvi um som incrível noite passada, um trompete tremendamente agudo'. 'Sim', eu disse, 'aquilo é um trompete piccolo'. 'Nós podemos usá-lo', ele me perguntou. 'Sim, claro que nós podemos', eu respondi. Eu nunca havia pensado nisso, mas ele imaginou isso. Então, nós trouxemos um rapaz da LSO (London Symphony Orquestra - David Mason) para tocar trompete piccolo e foi assim”.

14 “Ouvindo uma orquestra tocar 'A cavalgada das Valquírias' ou '1812 Overture' era como se pudesse ouvir a marcha de grandes exércitos. Por que um disco de rock não poderia soar tão grande, tão poderoso, tão arrebatador com isso?"
} 
repetições que visavam a permitir que o produtor encontrasse os melhores locais para fixar os microfones. Além da quantidade de músicos presentes na gravação, o outro segredo, na construção do wall of sound, consistia em posicionar adequadamente os microfones, de modo a não só captar os sons dos instrumentos, mas também os efeitos gerados pela reverberação dos mesmos pelo ambiente, o que explica o seu posicionamento, às vezes, aparentemente aleatório, longe dos instrumentos e dos amplificadores, como a ilustração abaixo revela:

Figura 1: Foto de uma sessão de gravação, em 1965 nos estúdios Gold Star, em Los Angeles ${ }^{15}$.

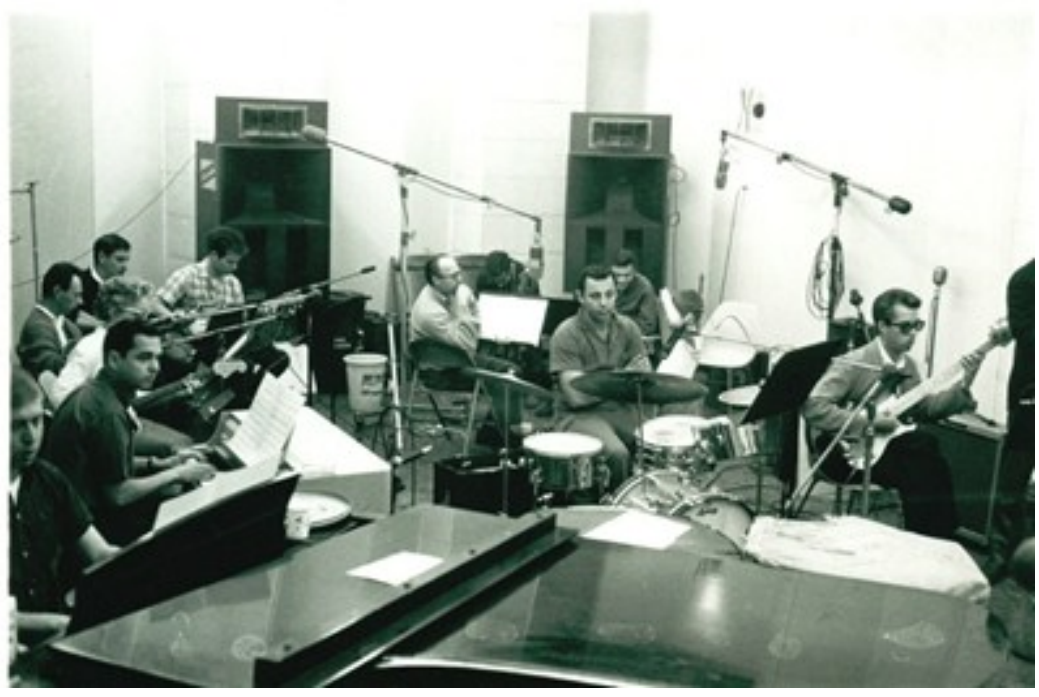

O wall of sound pode ser pensado, portanto, como uma técnica de criação daquilo que estamos chamando de ambiências pelo fato de consistir na construção técnica de um espaço-tempo à percepção que afeta a dimensão sensorial do ouvinte ao oferecer qualidades acústicas de natureza distinta daquela que compõem o espaço em que se realiza a audição. Em "Penny Lane", o modo de registro das várias camadas de piano que compõem a canção revela o emprego desta técnica:

The recording of Penny Lane was almost as complex as for Strawberry Fields Forever. To begin with, McCartney laid down six takes of the piano backing track, and onto track two of the final attempt he added a second piano to the latter half of each verse. Track three was filled with a third piano part as well as tambourine, both of which were recorded via microphone signals fed through a Vox guitar amplifier ${ }^{16}$. (BADMAN, 2000, p. 282).

Fonte: https://thebaronblog.wordpress.com/2012/05/31/phil-spector-the-troubled-genius-of-popproduction-part-1/. Acesso em: 30 jan. 2014.

16 “A gravação de Penny Lane foi quase tão complexa quanto foi a de Strawberry Fields Forever. No começo, McCartney fez seis takes de piano de fundo, e sobre a segunda pista, numa tentativa final, ele adicionou uma segunda parte de piano nas últimas metades de cada verso. A terceira pista foi preenchida com um terceiro piano, assim como um tamborim, ambos os quais foram gravados via sinais de microfone alimentados através de um amplificador de guitarra da marca Vox". 
Ao ouvirmos "Penny Lane", não percebemos sons de diferentes pianos isolados, mas uma massa sonora formada pelo timbre de vários outros registros de pianos. Seguramente, ouvidos menos treinados não são capazes de perceber a grande variedade de instrumentos que compõe a canção, tal como se pode constatar no exame da tabela abaixo:

Tabela 1: Lista de músicos e respectivos instrumentos usados na gravação de "Penny Lane"17.

\begin{tabular}{|l|l|}
\hline \multicolumn{1}{|c|}{ Músico } & \multicolumn{1}{c|}{ Instrumentos } \\
\hline Paul McCartney & Voz, backing vocals, três pianos e baixo \\
\hline John Lennon & Backing vocals, dois pianos, congas e palmas \\
\hline George Harrison & Backing vocals, sino e palmas \\
\hline Ringo Star & Bateria e tamborim \\
\hline George Martin & Piano \\
\hline David Mason & Trompete Piccolo \\
\hline Ray Swinfield, P. Goody e Manny Winters & Flautas e piccolos \\
\hline Leon Calvert, Freddy Clayton, Bert Courtley \\
e Duncan Campbell & Trompetes e flugelhorn \\
\hline Dick Morgan e Mike Winfield & \\
\hline Frank Clarke & Oboés e corne ingles \\
\hline
\end{tabular}

É relevante, ainda, salientar que esta "Penny Lane" foi registrada em uma nova tecnologia do período, uma mesa de quatro canais, o que conferia não só uma grande engenhosidade na incorporação de todos os instrumentos e takes gravados no processo de mixagem, mas também disponibilizava novos recursos e métodos para a construção de uma impressão global do som. No refrão de "Penny Lane", a ambiência irrompe no fato de não ouvimos as mudanças individuais dos acordes dos instrumentos, mas transformações harmônicas que se dão em bloco.

No verão de 1969, quando tinha 11 anos, comprei um sistema estéreo na loja de som perto de casa. Desembolsei os 100 dólares que tinha recebido aparando grama dos jardins vizinhos naquela primavera, a 75 cents a hora. Passava longas tardes no meu quarto

\footnotetext{
${ }^{17}$ Fonte: MACDONALD, Ian. Revolution in the head: The Beatle's records and the sixties. London: Pimlico, 2005. pp.221-223.
} 
ouvindo discos: Cream, Rolling Stones, Chicago, Simon and Garfunkel, Bizet, Tchaikovsky, George Shearing e o saxofonista Boots Randolph.

Daniel Levitin

A indústria fonográfica forjou como objeto de desejo, na década de 60 , sistema high fidelity. Sua aquisição representava status, conforto e, sobretudo, a possibilidade de fruição de uma qualidade sonora consideravelmente superior àquela oferecida pelos demais aparelhos de reprodução de áudio. Também conhecido pela forma abreviada $h i$ $f i$, este sistema de reprodução e amplificação elétrica de ondas acústicas apresentava como novidade a distribuição do som por dois canais; isto é, disponibilizava duas pistas de gravação de uma mesma canção que podia ser ouvida, consequentemente, em duas caixas com auto-falantes que ficavam separadas uma da outra de forma equidistante.

Produto do desenvolvimento tecnológico das "economias de mercado desenvolvidas" e de seu ímpeto pelo processo contínuo de inovação, o hi-fi trazia, em seu DNA, o selo de revolução tecnológica que, a partir dos anos 50, passou a orientar e estimular o consumo, tornando-se, como afirma Eric Hobsbawn, "o principal recurso de venda para tudo" (1995, p. 260). No caso específico deste sistema, a promessa oferecida era a de simular, no ambiente doméstico, uma qualidade sonora similar - com "alta fidelidade" - àquela proporcionada pela experiência de assistir a um concerto ao vivo, conforme os anúncios publicitários que circulavam no período atestam: "Now, you can enjoy the same sense of musical realism, of "presence", as if you are actually there. You not only hear the music, but you feel it with a sense of true personal participation"18.

Desde que Thomas Edison inventara, em 1877, o cilindro fonográfico, que a indústria musical perseguiu, obsessivamente, modos de aperfeiçoamento das técnicas de gravação e reprodução de áudio que permitissem desfrutar de um prazer auditivo no mesmo nível ou superior ao que se tinha na realidade. A gravação que o tenor Enrico Caruso realizou, em 1902, petrificou o público e o transformou no primeiro grande astro dos discos de cera, já que, segundo Alex Ross, "O tom agudo e metálico de Caruso, aquele latido de ouro, fazia o próprio homem parecer visceralmente presente" (ROSS, 2011, p. 78). Contudo, por ironia do destino, o que se viu, de Caruso à remasterização dos Beatles, realizada nos anos 90, foi um processo cada vez maior de "baixa fidelidade ao real", tendo em vista que, enquanto o fonógrafo simplesmente registrava um som a partir da pressão de um diafragma realizado pelo ato expiratório e sua consequente inscrição realizada por uma agulha sobre um cilindro, o sistema elétrico o amplificava e o digital, ao transformá-lo em códigos binários, reduzia enormemente o seu nível de ruído. Portanto, dizer que o sistema hi-fi apresenta um som similar à realidade é como afirmar que a imagem de um rosto em close up que vemos em uma tela de cinema simula a nossa percepção habitual.

O fato inequívoco é que as determinações desse novo aparato técnico passou a influir sobre os procedimentos estéticos empregados na produção de ambiências sonoras, na medida em que se cunhou certos processos estandardizados de construção

\footnotetext{
18 “Agora, você pode desfrutar do mesmo realismo musical, da 'presença', como se você estivesse realmente lá. Você não apenas ouve a música, mas você a sente com uma sensação de participação pessoal real". Hi-Fi Magazine. Março de 1954. p.30.
} 
de uma percepção de "tridimensionalidade auditiva", tornando o som mais "sólido" significado, a propósito, da palavra grega $\sigma \tau \varepsilon ́ \rho \varepsilon o ~(s t e r e o)$, que passou a caracterizar esse sistema. O fã que, em fevereiro de 1967, ouvisse o recém-lançado single ${ }^{19}$ dos Beatles, em um sistema $h i-f i$, teria, diante de si, um disco de 7" (sete polegadas), com 45 R.P.M. (Rotações por minuto), através do qual as vozes do coro e o som dos instrumentos eram, justamente, emitidos em diferentes volumes por duas caixas amplificadas. No entanto, essa mesma tecnologia que estandardizava procedimentos estéticos oferecia, também, novos recursos de expressão sonora que, em alguma medida, permitiam uma desorientação da produtividade programada, conforme aponta Daniel Levitin:

\begin{abstract}
Os artistas da nova geração que eu ouvia estavam todos explorando pela primeira vez as possibilidades de mixagem em estéreo. Como os alto falantes do meu sistema 'três em um' de 100 dólares não eram muito bons, eu nunca tinha ouvido música com a profundidade dos fones de ouvido: a localização dos instrumentos à esquerda e à direita, mas também no espaço frontal e traseiro (reverberante). (LEVITIN, 2010, p. 8).
\end{abstract}

Em "Penny Lane", a subversão técnico-estética - ainda que dentro dos limites da música pop - visando à construção de uma determinada atmosfera é perceptível no modo bastante singular como voz, backings, timbres de piano, peças de bateria, metais e cordas são distribuídos por diferentes canais, criando uma sonoridade que se projeta ao nosso redor, preenchendo parte substancial do espaço de espectro sonoro. Ainda nessa perspectiva, é notável também a incorporação de procedimentos em diálogo com a música concreta, como a inserção de sinos utilizados pelos bombeiros, no refrão, que ocupam uma espécie de segundo plano, dentro da experiência de "tridimensionalidade" sonora proporcionada pelo sistema $h i-f i$.

\title{
CONSIDERAÇÕES FINAIS
}

A partir de um primeiro problema, apontado por Simon Frith, de que o processo de remasterização musical lança as canções de bandas como os Beatles em uma espécie de "espaço virtual" entre os anos 60 e 80, iniciamos nossa exposição levantando algumas questões concernentes à relação entre técnica e experiência estética no domínio da cultura musical contemporânea. Propusemos, então, como forma de compreender mais profundamente estes fenômenos de natureza sonora, um exame voltado à ao processo de formação dessas texturas musicais, na clave daquilo que definimos como ambiências; a saber: "um continuum entre um espaço-tempo tecnicamente construído à percepção e os atos de engajamento afetivo que nele se desenvolvem". Nesse sentido, nossa atenção se voltou não ao processo de remasterização - que inequivocamente influi sobre o modo como percebemos uma canção hoje -, mas às ambiências próprias aos modos como a canção "Penny Lane" havia sido originalmente registrada, em 1967. Este método nos levou a investigar três elementos que, ainda que não sejam os únicos, são fundamentais para a constituição da natureza global da acústica da canção: a voz em

19 Disco que veicula uma única faixa como forma de divulgação de uma das canções do álbum de um artista. 
performance, os sistemas de gravação (wall of sound), de pós-produção e reprodução (hi-fi). Agora, ao final, gostaríamos de retomar a questão central apresentada no início desse texto: de que modo a construção de ambiências sonoras influi, hoje, sobre a dimensão afetiva de um ouvinte?

Uma primeira conclusão é a de que essa natureza híbrida da sonoridade das canções, que as lança para um entre-lugar histórico, em termos de estética musical, é, por um lado, um fenômeno decorrente dos imperativos econômicos que regem a circulação das mesmas e que afetam a sua própria natureza, ao transformar em códigos binários as informações acústicas originalmente registradas em sistemas elétricos - 0 que cria, evidentemente, determinações estéticas, tanto sob o ponto de vista das sonoridades, como do próprio modo de composição. Mas, por outro, esse amálgama é também composto por sonoridades que apresentam especificidades acústicas e estéticas inscritas na própria materialidade da mídia em que a canção foi originalmente registrada. Desse modo, voltando a Frith, a sonoridade apresentada pelas reedições dos Beatles se situaria, em termos estéticos e acústicos, em um "espaço virtual" entre os anos 60 e os 90 .

Uma segunda, de caráter mais especulativo, é a de que, sob o ponto de vista da relação entre técnica e experiência estética no domínio da cultura musical contemporânea, essa sonoridade híbrida que nos permeia, parece atestar que vivemos um presente invadido, materialmente, pelas reverberações de ambiências do passado. Desde que se ouviu as primeiras emissões de áudio do gramofone, como nos conta Friedrich Kittler, que Thomas Edison vaticinou que, a partir daquele momento, a fala tinha se tornado "imortal" (KITTLER, 1999, p. 21). Contudo, levando a proposição de Edison às últimas consequências, é a própria ambiência sonora; sua acústica, a textura musical, os recursos tecnológicos e sistemas estéticos de um determinado período histórico que se imortalizam. A experiência nostálgica despertada naqueles cresceram ouvindo canções no rádio AM quando têm a oportunidade de ouvi-las novamente, com a mesma natureza acústica com a qual estavam acostumados, ou o uso que bandas novas fazem de instrumentos antigos e tecnologias analógicas para emular características sonoras de grupos de rock dos anos 60 ou 70, são alguns exemplos que parecem ratificar essa tese. Como se vê, o estudo da dimensão material ilumina questões relativas à experiência subjetiva.

Dentro dessa perspectiva, o exame das ambiências em "Penny Lane" evidenciou que, não obstante o papel dos processos de remasterização ou de mudança de mídia sonora, há, de fato, na textura musical formada por voz, instrumentos e sistemas de gravação e pós-produção, certas qualidades acústicas originalmente registradas, cujo rastro está presente, de forma material, na canção, como uma espécie de componente acústico-imanente do passado. É possível ouvi-la nas oscilações de intensidade no modo como é cantada, na suavidade da maneira como é tocada, ou na sensação de preenchimento dos espaços quando chega o refrão; enfim, nesse continuum entre o espaço-tempo tecnicamente construído à percepção e os atos de engajamento afetivo através dos quais "Penny Lane" se enraíza em nosso corpo, nos nossos ouvidos e olhos. 
BADMAN, Keith. The Beatles off the record. London: Book Sales Limited, 2000.

BENJAMIN, Walter. "A obra de arte na era de sua reprodutibilidade técnica". In: Benjamin e a obra de arte: técnica, magia e percepção. Rio de Janeiro: Contraponto, 2012.

BENVENISTE, Émile. Problemas de linguística geral I. Campinas, SP: Pontes Editores, 2005.

BROWN, Mick. Tearing down the wall of sound: the rise and fall of Phil Spector. New York: Vintage Books, 2008.

CUNHA, Newton. Dicionário Sesc: a linguagem da cultura. São Paulo: Perspectiva: Sesc São Paulo, 2003.

DELEUZE, Gilles. O que é a filosofia? São Paulo: Editora 34, 1992.

. Francis Bacon: lógica da sensação. Rio de Janeiro: Jorge Zahar Ed., 2007.

FAVARETTO, Celso. Tropicália, alegoria, alegria. São Paulo: Ateliê Editorial, 2000.

FRITH, Simon. "Can music progress? Reflections on the history of popular music". Fonte:

http://www.doiserbia.nb.rs/img/doi/1450-9814/2007/1450-98140707247F.pdf. Acesso em 5 de outubro de 2015.

GUMBRECHT, Hans Ulrich. Atmosfera, ambiência, Stimmung. Rio de Janeiro: Contraponto, PUC, 2014.

HOBSBAWN, Eric. Era dos extremos. São Paulo: Companhia das Letras, 1995.

HOLMES, Thom. The Routledge guide to music technology. New York: Taylor \& Francis Group, 2006.

HOUAISS, Antônio; VILLAR, Mauro de Salles. Dicionário Houaiss da Língua Portuguesa. Rio de Janeiro: Objetiva, 2001.

LEVITIN, Daniel. A música no seu cérebro. Rio de Janeiro: Civilização Brasileira, 2010.

MACDONALD, Ian. Revolution in the head: The Beatle's records and the sixties. London: Pimlico, 2005.

MOORE, Alan F. The Beatles: Sgt. Pepper's lonely hearts club band. Cambridge: Cambridge University Press, 1997.

ROSS, Alex. "Máquinas infernais: Como as gravações mudaram a música". In: Escuta só: do clássico ao pop. São Paulo: Companhia das Letras, 2011.

ROYLANCE, Brian (Org.). The Beatles Anthology. London: Cassel \& Co., 2000.

SINGER, André. “Crítica e autocrítica em Sgt. Pepper, 40 anos”. In: Piauí. Junho, 2007.

SPITZER, Leo. “Milieu and ambience”. In_Essays in historical semantics. New York: Russel \& Russel, 1968.

TATIT, Luiz. Elos de melodia e letra. Cotia, SP: Ateliê Editorial, 2008.

WISNIK, José Miguel. O som e o sentido. São Paulo: Companhia das Letras, 1989.

Recebido em 05/10/2015. Aprovado em 05/11/2015.

Title: The sound around: ambiences, affects and audio technologies in "Penny Lane"

Abstract: This paper aims to understand how the material dimension of vocal performance and audio recordings and reproductions influences the process of building a kind of sensory experience that we usually call atmosphere, mood or ambience. Within this perspective, we will focus on the song "Penny Lane", by the Beatles, in order to think of the inflexions of the technique in the realm of the affections, as well as the way we attribute senses when we listen to a song and also in the realm of cultural experience of listening.

Keywords: Ambiences. Affections. Audio Technologies. Beatles. Penny Lane. 